\title{
THE REAL CLIMATE DEBATE
}

\begin{abstract}
In the scientific community, the big question is not whether action on climate change is required, but what form it should take - and the part that scientists should play. Three Nobel laureates and three early-career researchers gave their thoughts to Nature on the current state of climate action worldwide and the place of science in society.
\end{abstract}

\section{INTERVIEWS BY RICHARD HODSON}

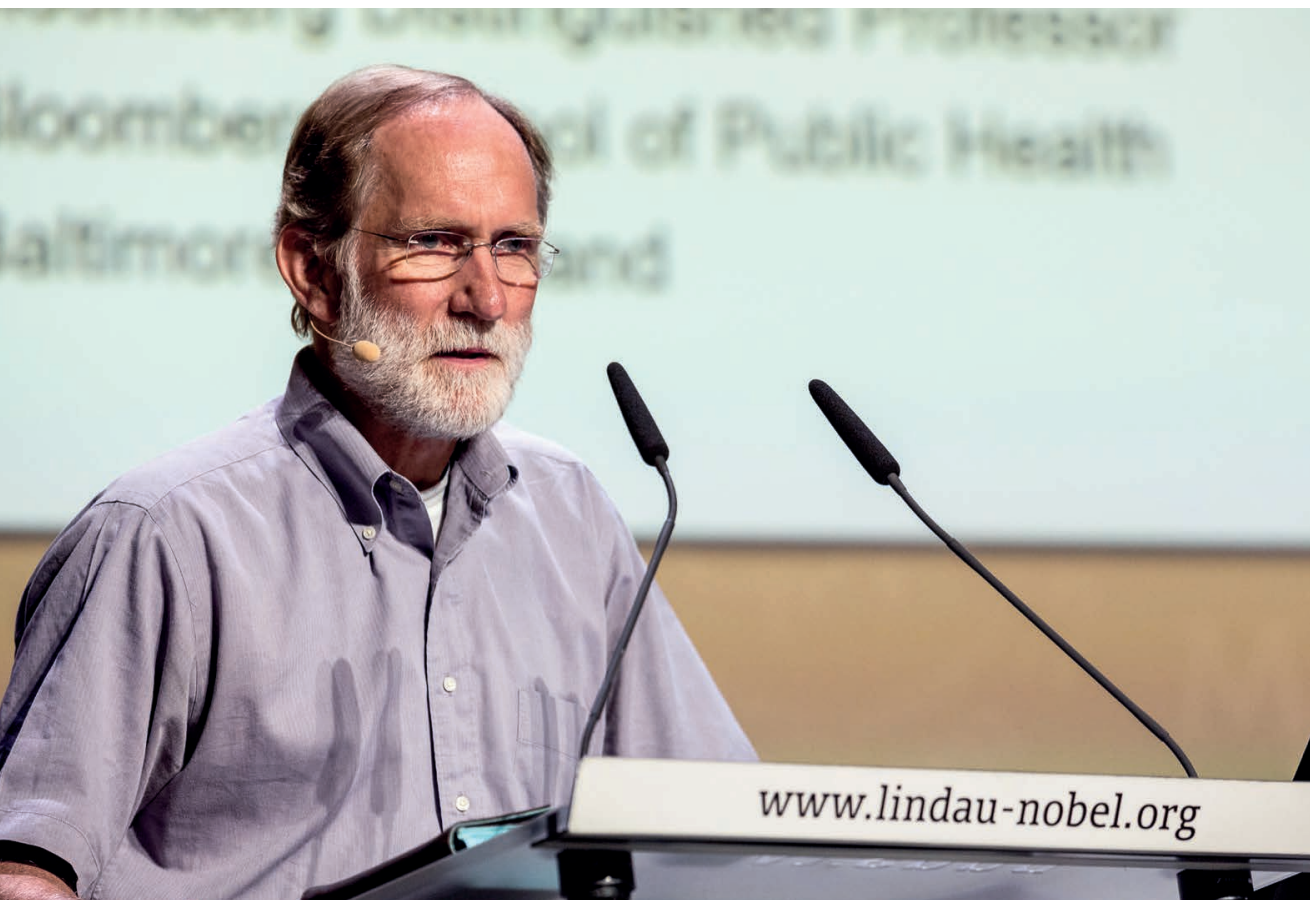

PETER AGRE

“Winning elections is a lot more important thanfeel-good activities."

Is US president Donald Trump's decision to pull the United States out of the 2015 Paris climate accord a blow?

I am humiliated and disappointed that Trump is in a position to create policy. I don't consider him qualified, and I don't think he's responding to evidence. But I doubt that pulling out of the Paris climate agreement will change the minds of the majority of Americans who find climate change concerning.

Why has the response to climate change been much slower and more adversarial than to public-health issues?

Climate change is different because the onset is not immediate. It's the immediacy and the effect on the individual family member that make health threats a problem we have to deal with right now - as opposed to climate change, which will create problems in a hundred years when everything will be different anyway. Geological time is beyond us.

What can scientists in the United States do to engage the general public on climate change? In the end, people will support action on climate change if they can understand it. I think more scientists should step up and go to the public - but not to lecture people. To be morally correct is important, but to be convincing is more important.

Sadly, scientists are not very good communicators, even of their own work to other scientists. They tend to overdo the minutiae and lose the importance of the topic. That's a problem. It's important to choose words carefully — just talking about 'natural selection' rather than 'evolution', for example, can make it much easier to talk about antibiotic resistance with elements of the religious right-wing. Communicating requires subtlety and sincerity. We could do a lot better.
What about public demonstrations? Did you take part in the March for Science?

No, I was polluting the atmosphere flying back from Denmark after a long-planned trip. If I had been in the United States I might have, but I saw the march more as an exercise for people who were upset, rather than something that was going to change policy. I don't think it had any positive effect whatsoever on Trump.

I'm also constantly requested to sign petitions. But I'm pretty doubtful that those things change anybody's mind. I think winning elections is a lot more important than feel-good activities.

How politically active do you think scientists should be?

I think some should run for public office. We have a dearth of elected representatives with scientific training, but they are very helpful. When the voting occurs, they're in the room.

Some have been very good. Rush Holt Jr was a physicist and an eight-term congressman; now he's head of the American Association for the Advancement of Science. When he ran for office the bumper stickers in his New Jersey district said "My congressman is a rocket scientist". He wasn't - he was a nuclear physicist — but being a scientist was part of his platform. And Harold Varmus, he was very good. Varmus won the Nobel Prize in Physiology or Medicine in 1989, but he was an English major to begin with and he was articulate, precise and incredibly insightful. I think Varmus can be individually thanked for convincing then-President Bill Clinton to double the US National Institutes of Health budget when Varmus was director.

We have to be careful not to overdo things sometimes I think too much visibility brings a lack of trust. But working with public figures is important, and maybe some of today's young scientists will run for elected office. Twentyfive years from now, they could be in Congress and really able to do something positive. To put aside your science is a huge sacrifice, but there'll be a reward. And the reward will be important for all of us.

Peter Agre is director of the Johns Hopkins Malaria Research Institute in Baltimore, Maryland. 


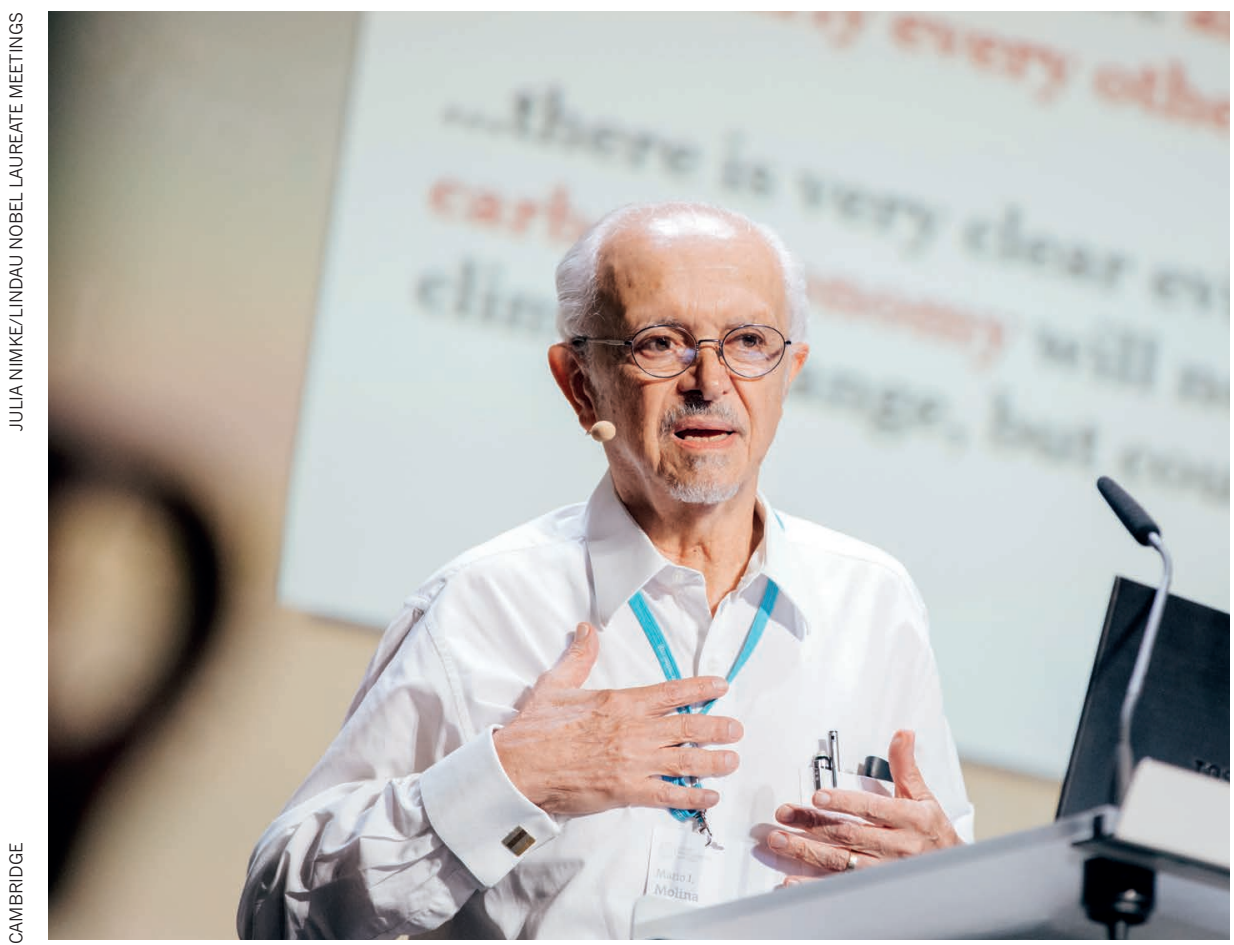
MARIO MOLINA

\section{"It's become a matter of belief, however irrational."}

\section{How do you feel about the current state of} climate policy in the United States?

It is extraordinarily worrisome. Science tells us very clearly that we are putting millions of people at very high risk if we continue to function in a business-as-usual manner. We don't accept risk for people flying, or living in tall buildings in earthquake zones. But here we're risking gigantic disasters for humanity. It is extremely irresponsible and unethical to neglect the welfare of future generations.

Why has action on global warming been much harder to achieve than on ozone depletion?

Ozone depletion and climate change have some important differences. For one thing, there were a relatively small number of very large chemical companies involved in producing the ozone-depleting compounds. Those companies were, of course, initially opposed to any regulation, but they were able to make alternative compounds that allowed us to continue using refrigeration and aerosols without affecting the ozone layer. By contrast, climate change is tied to the use of fossil fuels. They're pervasive and they're crucial to the functioning of society - and therefore much harder to control.

The other thing that happened is that the climate issue became politicized. Scepticism has become a mantra of the Republican party in the United States, which currently holds the presidency, both houses of Congress and a majority of state legislatures. That unwillingleadership to accept the reality of climate change makes the problem much more difficult to deal with. It's become a matter of belief, however irrational.

\section{What can scientists do about it?}

We normally think that the first step is to go to the people in power - after all, they're the ones who can implement the changes we need, so we should make sure they're well informed. But this approach can backfire if you don't do it in the proper way, and right now it is hard to see how the people in power in the United States can be convinced through rational argument. There are indications that rational thinking is taking a back seat in other parts of the world as well, and that's extremely worrying.

If scientists learned to communicate more effectively we might be able to affect government functions, but probably not in the near future. That doesn't mean we should give up - there are many organizations, such as city councils and industrial companies, that are continuing to behave rationally in spite of what is going on in the federal government - but we do need to think about longer-term solutions. My expectation is that we will eventually deal with the problem through education, by communicating the enormous importance that science has and how it benefits society and our standard of living.

Mario Molina is professor of chemistry at the University of California, San Diego. ness by a large part of the country's political
JULIE FENTON

Graduate student,

Pennsylvania State

University, USA

It's hard for scientists

to make definitive

statements about the

'truth'. Just as we don't

believe exactly the

same things as we did

50 years ago, we expect

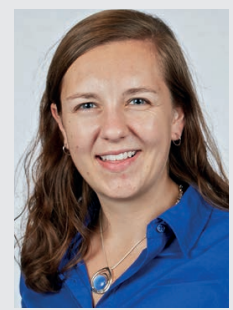

our understanding of the things we're learning now will change over time. It doesn't mean our current understanding should be dismissed as incomplete, but it can be a challenge to communicate this concept to non-scientists.

It's become evident that my communication skills are something I have to invest time in. It's too easy to forget that we have a broader responsibility to the public. In my experience, public engagement is not a routine part of academic training. Every scientist can start by talking with people they know in their everyday lives. That's not hard.

\section{KAREN STROOBANTS}

Postdoctoral researcher, University of Cambridge, UK

I strongly agree that more people with scientific training should seek careers in policy, but we are failing to encourage them.

People from academic

backgrounds are made to feel as though they have failed as scientists when they choose to take their career in another direction.

I'm thinking about going into policy — not because my research isn't good enough, but because it's something I love as much as chemistry. It's a difficult decision to make, made harder by the fact that I feel as though I will be judged as a failure for leaving my field. We have to make PhD students aware that working in a think tank or as a public official is a positive career choice through which they can be valuable - and not a negative step.

\section{THOMAS GIANETT}

Assistant professor,

University of Arizona,

USA

There is a fracture between the scientific world and the political world, especially in the United States, and think we have a duty as

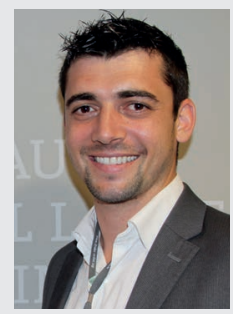

scientists to repair it. Getting more researchers into policymaking, even temporarily, could help. But when you're facing people who have thought in a particular way for 40 or so years, it will be hard to change minds. What might be smarter is to focus on education and shaping young minds.

We should also remember that there are still many technical challenges surrounding climate change. Nitrous oxide, for instance, is a relatively neglected, yet extremely potent, greenhouse gas. We need to communicate better, but we also have many scientific problems left to solve. 


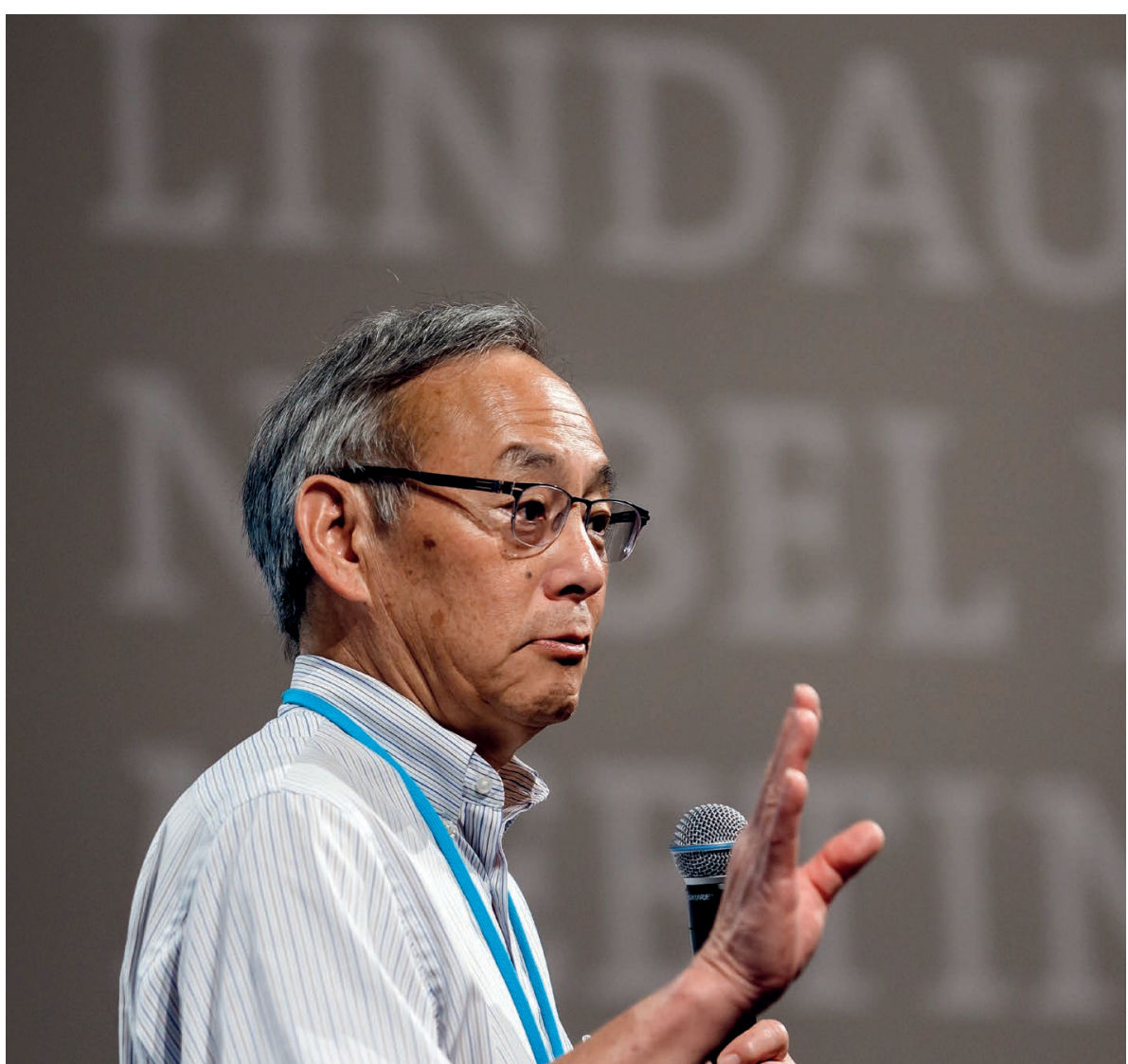

\section{STEVEN CHU}

\section{“It's especially useful to have scientists in cabinet-level positions.”}

\section{Is the Paris climate accord less significant now} that the United States intends to leave?

The Paris agreement is still an important signal of international consensus. With the Copenhagen agreement in 2009, the developing world said to the rest of the world "you created this mess - you fix it". Now there is recognition that it is a world problem, and Europe and China are not going to pull back on their efforts to head off climate change just because the United States is trying to. There are too many engineers in the Chinese government for it to turn its back on scientific evidence.

\section{How have views on climate change become so polarized in the United States?}

Al Gore took a strong public stance on climate change, and I admire that. But he is a prominent Democrat, and many Republicans have since made climate-change scepticism part of their political identity. Now we have a Republican head of the US Environmental Protection Agency, Scott Pruitt, who simply doesn't believe that the climate's changing - or if it is, that it's not due to human actions. The other thing is that there are a lot of fake facts floating around

knew what was going on with lung cancer in the 1960s and 1970s, the oil and gas industry know what's going on with climate change. Some companies are looking for solutions; others want to muddy the waters.

\section{Have scientists provided enough good} information on climate change to the public? We can do better. Climate is a very complex thing to simulate. The failure to predict the global temperature plateau that we experienced from 2002 to 2012 was held up as proof that climate scientists didn't know what was going on. We now know that the models failed to accurately predict the subtle changes in warming of the deep oceans, although when averaged over two decades they were accurate.

We've also underestimated the extent of many alarming changes, and it's still hard to predict with any precision what's going to happen; the full effects of greenhouse-gas emissions won't be seen for at least a hundred years. It's like going to your doctor and saying "I'm 32 kilos overweight and I smoke, but unless you can predict exactly what's going to happen to me and when, I'm not going to give up cheesecake and cigarettes". No patient would demand that of their doctor, so why should we demand it of climate scientists before we take action?

\section{What can scientists do to change things?}

We have clear data to show that the rise in atmospheric carbon dioxide is due to human activity. Such scientific arguments are not going to sway the Scott Pruitts of this world. But if we could develop climate-friendly technologies that are no more expensive than current technology, the manufactured fear will disappear.

\section{What sort of technologies do you think are essential to reduce emissions?}

We need electric vehicles with batteries that can be charged up for a 160-kilometre trip in 6 minutes. That's one of my pet projects. If we can increase the energy density of electric vehicles threefold, at no additional cost, then electric vehicles will simply be a better choice for most people than internal-combustion engines.

The current US administration wants to kill a lot of this applied research. As well as de-funding climate research, it has called for the elimination of the US Advanced Research Projects Agency-Energy (ARPA-E), which was founded during my time as energy secretary in the Obama administration. The House of Representatives went along with the cut, but the Senate wants to preserve the programme, so let's hope that sanity prevails. A cynical view of what is happening is that new clean-energy technologies that are competitive, or better than competitive, with incumbent ways of generating energy are the last thing opponents of change want to see developed.

\section{Would more researchers getting involved in} politics, as you did, be fruitful?
Yes. It's especially useful to have scientists in cabinet-level positions. They are heads of agencies, they have budgets, and that allows them to do far more than any single senator or congressperson.

When I became energy secretary in 2009, I was the first scientist to be a cabinet member in the history of the United States. I was very connected to the scientific world, so I was able to identify and recruit a lot of researchers who had never dreamed of joining the government. I spent a lot of time with them, not to micromanage their decisions but to sit and brainstorm. My job was to bring in very good people, cover their backs and let them do their jobs.

Do scientists have to drop their research to get involved in government?

I think most would have to. I was still a practising scientist - I couldn't abandon my graduate students - but it wasn't easy. As then vice-president Joe Biden said to me, "You're one sick puppy!” I was willing to spend vacations and the wee hours of Saturday night working on research. But most people aren't that crazy.

Steven Chu is professor of physics and molecular and cellular physiology at Stanford University, California.

Interviews have been edited for length and clarity. 